\title{
For Supplier Evaluation Process through Fuzzy PROMETHEE Method
}

\author{
Rahmi Baki
}

\begin{abstract}
With increasing competition, high performance of organizations does not only depend on their individual performance but also on the performance of the other associates in the supply chain. Given the significant impact of the associates, it is clear that selection of a supplier is of great importance for organizations. In the present study, one of the decision making techniques, Fuzzy PROMETHEE technique, was employed to compare suppliers. Fuzzy sets were used to get rid of uncertainties in the evaluation process and due to easiness they offer to get the evaluation of decision makers orally.
\end{abstract}

Index Terms-Multi criteria decision making, supplier selection, fuzzy PROMETHEE.

\section{INTRODUCTION}

In today's competitive world, the efficiency of a firm is evaluated not only through its own performance but also through the management of the supplier chain [1]. Effective accomplishment of supplier selection enhances the competitive advantage and effectiveness of a firm and reduces its expenditures. Supplier selection is directly associated with the success of firms. The number of studies dealing with the evaluation and selection of suppliers is continuously increasing. In recent years, many decision support methods have emerged for the selection of the most effective alternative complying with the determined criteria. One of these methods is PROMETHEE.

When compared to other multi-criteria decision making methods, PROMETHEE is not difficult to understand and apply. Moreover, it can be administered to problems that should be compared in terms of more than one criterion [2]. However, in PROMETHEE method, it is highly probable to conduct incorrect evaluations and to reach erroneous conclusions due to uncertainties in input values used. In order to prevent this, Fuzzy PROMETHEE method was developed by combining fuzzy numbers with PROMETHEE method [3].

In today's highly competitive environment, the performance of a firm does not only depend on its own capabilities. With the development of supply chain management, fiercer competition started to be experienced between the supply chains of the firms.

An effective supply chain combines the internal resources of a firm with the external resources so that it can operate efficiently. In this way, variable such as production capacity, market sensitivity and customer-supplier relationships that

Manuscript received March 29, 2015; revised June 7, 2016.

R. Baki is now with the Department of Management Information Systems, Aksaray University, Aksaray, 68100 Turkey (e-mail: rahmi.baki@aksaray.edu.tr). affect the whole performance of an organization can be enhanced. Working with the suitable supplier reduces expenditures, improves customer satisfaction and enhances the organization's competitive power. Purchasing activities, costs of raw materials and intermediate products account for nearly $70 \%$ of the total costs incurred by the activities of an organization.

Large scale organizations do not usually go on using the same supply chains when strategies and markets are changed. They adjust their supply chains to their emerging needs. However difficult this adjustment process is, it is critical for the development of the supply chain. Many organizations do not think that their supply chains will meet sudden changes in supply and demand and permanent changes in the market. Such structural changes result from economic developments, political and social changes and changes in demographic tendencies and technologies. As long as they do not adjust their supply chains to changing situations, firms cannot remain competitive for a long time.

\section{DETERMINATION OF THE CRITERIA TO BE USED IN THE EVALUATION OF SUPPLIER PERFORMANCE}

Determination of the criteria is the most importance stage of supplier selection. When the criteria are not suitable for the needs, in the following stages of the process, they may result in waste of time and money. The criteria should be determined based on the structure, needs and goals of the firm that will select the supplier. The firm should consider what is important for itself while selecting its supplier.

A study dealing with the determination of criteria in supplier selection was conducted by Dickson. Dickson conducted the study with the participation of 273 purchasing officials and managers selected. At the end of the study, 23 basic criteria were determined to be used in the process of supplier selection [4].

When the study of Dickson is examined, it is seen that the most important criterion is quality. Weber et al. conducted a meta-analysis on 74 studies including supplier selection criteria developed based on the Dickson's criteria and conducted as of 1996 and reported that the criterion most discussed is net price. It is followed by the criteria of distribution and quality [5].

Fawcet determined quality of cost, distribution, flexibility and novelity as the most important criteria in supplier selection [6]. Ghodsypour and O'Brien reported that the most important criteria should be quality of the cost and service [7].

$\mathrm{Hu}$ reviewed the studies conducted as of 1991and found that price, quality, production capacity and distrubition are the most important criteria in the selection of a supplier. Thus, 
it was concluded that price, quality, production capacity and distribution are the most important criteria in the selection of a supplier [8].

In the current study, alternative suppliers were compared for the selection of the best supplier for an international construction firm. The criteria to be used in the comparison of the alternative suppliers were determined through an extensive literature review and analysis of the opinions of the managers who are concerned with the issue. The criteria to be used in the current study for the evaluation of the performances of the alternative suppliers were determined to be quality, price, delivery, guarantee, technical competence, flexibility and background of the organization.

Determination of the Criteria to be Used in the Evaluation of Supplier Performance.

\section{DETERMINATION OF THE CRITERIA TO BE USED IN THE EVALUATION OF SUPPLIER PERFORMANCE}

Determination of the criteria is the most importance stage of supplier selection. When the criteria are not suitable for the needs, in the following stages of the process, they may result in waste of time and money. The criteria should be determined based on the structure, needs and goals of the firm that will select the supplier. The firm should consider what is important for itself while selecting its supplier.

A study dealing with the determination of criteria in supplier selection was conducted by Dickson. Dickson conducted the study with the participation of 273 purchasing officials and managers selected from American and Canadian Society of Purchasing Managers. At the end of the study, 23 basic criteria were determined to be used in the process of supplier selection [4]

When the study of Dickson is examined, it is seen that the most important criterion is quality. Weber et al. conducted a meta-analysis on 74 studies including supplier selection criteria developed based on the Dickson's criteria and conducted as of 1996 and reported that the criterion most discussed is net price. It is followed by the criteria of distribution and quality [5].

Fawcet et al. determined quality of cost, distribution, flexibility and novelty as the most important criteria in supplier selection [6]. Ghodsypour and O'Brien reported that the most important criteria should be quality of cost and service [7].

$\mathrm{Hu}$, reviewed the studies conducted as of 1991 and found that price, quality, production capacity and distribution are the most important criteria in the selection of a supplier. Thus, it was concluded that price, quality, production capacity and distribution are the most important criteria in the selection of a supplier [8].

According to Lee, contrary to the popular belief, supply chains focusing on speed and cost lose their effectiveness in the long run. Organizations that can construct active, adjustable and compatible can perform better than their rivals When one of these elements is missing, then the supply-chain cannot operate efficiently.

Paranhinski and Benton determined the criteria as quality, delivery performance, responsiveness to changing demands, service support and general performance [9]-[20]. Liu and Hai, on the other hand, determined quality expectation, cost efficiency, reliability of delivery, flexibility of volume and information and customer services as the most important criteria [21].

In recent studies, the criterion of cost has not been elaborated well enough. Moreover, the main criteria seem to be similar in general.

In the current study, alternative suppliers were compared for the selection of the best prefab supplier for an international construction firm. The criteria to be used in the comparison of the alternative prefab suppliers were determined through an extensive literature review and analysis of the opinions of the managers who are concerned with the issue. The criteria to be used in the current study for the evaluation of the performances of the alternative suppliers were determined to be quality, price, delivery, guarantee, technical competence, flexibility and background of the organization.

\section{FUZZY PROMETHEE METHOD}

In recent years, many methods have been developed to make a selection from among alternatives based on some certain criteria. One of these methods is "The Preference Ranking Organization Method For Enrichment Evaluation" (PROMETHEE) method. PROMETHEE method is a multi-criteria decision making method developed by Brans et al. [9]. When compared to other methods, it is relatively easier, more effective and flexible to implement.

Because of its easy implementation and mathematical features, PROMETHEE method has been used widely and successfully. However, when the evaluation of criteria is based on data taken from daily-life, they become difficult to express numerically. This may result in loss of data. A combination of fuzzy sets and PROMETHEE, Fuzzy PROMETHEE technique was developed to solve this problem.

Geldermenn et al. conducted a life-cycle evaluation in iron and steel industry by using Fuzzy PROMETHEE technique [10].Goumas and Lygerou employed Fuzzy PROMETHEE method to evaluate the alternatives of energy absorption plans belonging to a geothermal zone [11]. Chou et al. conducted a case study to evaluate the eco-technologic method suitable for Shihmen basin in Taiwan by using PROMETHEE technique [12]. Zhang et al. employed Fuzzy PROMETHEE technique to rank the contaminated areas based on risk evaluation paradigms [13]. Chen et al. developed a method to design an external resource utilization strategy for information systems [14]. Moradpour et al. developed a Fuzzzy PROMETHEE technique to rank the preferences in highway construction projects [15]. Y1lmaz and Dağdeviren developed a Fuzzy PROMETHEE technique to be used in equipment selection problems [3]. Gupta and Bhardwaj developed a method to select logistic service providers for cement industry [16]. Chen proposed a new approach called "Interval Type-2 Fuzzy PROMETHEE" [17]. Elevli developed a method to make decisions about logistic transportation centers [18]. Peng et al. conducted an online customer analysis on mobile phone users in Chine region by using Fuzzy PROMETHEE technique and thus compared different mobile phone models [19].

The stages and operations of Fuzzy PROMETHEE method 
are summarized below.

Stage 1: Determination of alternatives, criteria and weights of the criteria

At this stage, alternatives to be evaluated, criteria to be employed to compare the alternatives and importance weights of the criteria are determined. As the sum of weights in PROMETHEE method should be 1 , weights cannot be fuzzy sets.

Stage 2: Evaluation of the alternatives

The alternatives are subjected to evaluation based on each criterion by decision makers. While evaluating the alternatives, linguistic variables are used. In PROMETHEE technique, making decision in ambiguous and fuzzy real life conditions is difficult. Therefore, while evaluating the alternatives, fuzzy sets are used.

Stage 3: Definition of preferences

Preference threshold values ( $q$ and $p$ ) are taken as certain numbers. $q$ and $p$ are not fuzzy numbers to prevent evaluations from being ambiguous due to a stretched form of a fuzzy number. It is necessary to determine $q$, the indifference threshold for the fifth type function, and $p$, certain preference threshold value. The values $q=0$ and $p=0.60$ were taken as the most suitable for the data.

In order to conduct the operation in the new function obtained, it is necessary to possess the basic information about operations with fuzzy sets. The procedure followed for subtraction operation to be conducted in our application is given in Equation 1.

$\left(l_{1}, m_{1}, u_{1}\right)(-)\left(l_{2}, m_{2}, u_{2}\right)=\left(l_{1}+u_{2}, m_{1}-m_{2}, u_{1}-l_{2}\right)$

As the values to be found will be fuzzy numbers, they should be converted into their absolute forms through yager index. Counterpart of a fuzzy number according to yager index can be calculated as $f(m, a, b)=\left(3^{*} m-a+b\right) / 3$.

While defining the preferences, preference functions for the criteria are identified. The preference functions are determined according to the structure of the criterion and basic features of the alternatives. In the method, 6 different preference functions are used. In our application, at the stage of setting up the preference functions, linear preference function (5th type) that is the most frequently used in Fuzzy PROMETHEE applications and the most suitable for the characteristic of the problem was selected.

$$
\begin{array}{cc}
P(\boldsymbol{\alpha}, \boldsymbol{\beta})=\mathbf{0}, & \mathbf{d}_{\mathbf{j}}<\mathbf{q} \\
P(\boldsymbol{\alpha}, \boldsymbol{\beta})=\frac{\mathbf{d}-\mathbf{q}}{\mathbf{p}-\mathbf{q}}, & \mathbf{q}<\mathbf{d}<\mathbf{p} \\
P(\boldsymbol{\alpha}, \boldsymbol{\beta})=\mathbf{1}, & \mathbf{d}>\mathbf{p}
\end{array}
$$

In Fuzzy PROMETHEE technique, the difference between the performances of $\alpha$ and $\beta$ actions in Equation 3 is expressed as $(n, c, d)$ fuzzy number.

$$
\begin{gathered}
P(\boldsymbol{\alpha}, \boldsymbol{\beta})=\mathbf{0}, \quad \mathbf{n}-\mathbf{c}<\mathbf{q} \\
P(\boldsymbol{\alpha}, \boldsymbol{\beta})=\frac{\mathbf{d}-\mathbf{q}}{\mathbf{p}-\mathbf{q}}, \quad \mathbf{q}<\mathbf{n}-\mathbf{c} \text { and } \mathbf{n}+\mathbf{d}<\mathbf{p} \\
P(\boldsymbol{\alpha}, \boldsymbol{\beta})=\mathbf{1}, \quad \mathbf{n}+\mathbf{d}>\mathbf{p}
\end{gathered}
$$

Through the values obtained, the comparison matrix is reached.

Stage 4: Evaluation of the alternatives according to the weights of the criteria

As this stage, the calculated comparison matrix is multiplied by the weight criteria. Thus, weighted comparison matrix obtained.

Stage 5: Ranking of the alternatives

Based on the data in the weighted matrix and the formulas in the Equations 4 and $5, \Phi^{+}$and $\Phi^{-}$values are calculated.

$$
\begin{aligned}
& \Phi^{+}(i)=\frac{1}{m-1} \sum_{i=1}^{m} \mu(x, y) \\
& \Phi^{-}(i)=\frac{1}{m-1} \sum_{i=1}^{m} \mu(y, x)
\end{aligned}
$$

By using $\Phi^{+}$and $\Phi^{-}$values, the required results with PROMETHEE I and PROMETHEE II are obtained. The values are compared through PROMETHEE I and preliminary ranking of the preferences is conducted. When one of the conditions in the Equations 6, 7, 8 is realized, it can be argued that alternative $a$ is superior to alternative $b$. When the Equation 9 is satisfied, it can be argued that the two alternatives are at the same level of preference.

$$
\begin{aligned}
& \Phi^{+}(a)>\Phi^{+}(b) \text { and } \Phi^{-}(a)<\Phi^{-}(b) \\
& \Phi^{+}(a)>\Phi^{+}(b) \text { and } \Phi^{-}(a)=\Phi^{-}(b) \\
& \Phi^{+}(a)=\Phi^{+}(b) \text { and } \Phi^{-}(a)<\Phi^{-}(b) \\
& \Phi^{+}(a)=\Phi^{+}(b) \text { and } \Phi^{-}(a)=\Phi^{-}(b)
\end{aligned}
$$

If one of the Equations 10 and 11 is satisfied, then the two alternatives cannot be compared through PROMETHEE I method.

$$
\begin{aligned}
& \Phi^{+}(a)>\Phi^{+}(b) \text { and } \Phi^{-}(a)>\Phi^{-}(b) \\
& \Phi^{+}(a)<\Phi^{+}(b) \text { and } \Phi^{-}(a)<\Phi^{-}(b)
\end{aligned}
$$

Through PROMETHEE I method, the partial ranking is obtained. In order to obtain the complete ranking of the alternatives, PROMETHEE II technique is employed. Through the difference between the positive and negative values, net flow is obtained and the alternatives are then compared based on this value.

$$
\Phi^{n e t}(a)=\Phi^{+}(a)-\Phi^{-}(a)
$$

\section{CONCLUSION}

In today's destructive competitive environment, companies must give importance to supply chain management to survive. A well-functioning supply chain provides to increase both market share and competitive advantages of companies. As a result of competition, shorter product life time, the customers' better quality, faster, cheaper, and different goods and services requirements have been become mandatory to pass a portion of the activities of companies to experienced suppliers. This also increases the importance of suppliers to work together. Supplier selection that is so important for companies is a multi-criteria decision making problem which includes both qualitative and quantitative criteria some of which can conflict with each 
other. In this study, to determine the best material handling system alternative, PROMETHEE approach is utilized. With the aim of taking into account the vagueness in the evaluation process and obtaining decision maker evaluations in an easier way with linguistic terms, fuzzy sets are utilized. To this end, a modified version of PROMETHEE is used.

\section{REFERENCES}

[1] S. Park, J. L. Hartley, and P. Wilson, "Quality management practise and their relationship to buyer's supplier ratings: A Study in the Korean automotive industry," Journal of Operational Management, vol. 19, pp. 695-712, 2001.

[2] R. U. Bilsel, G. Büyüközkan, and D. Ruan, "A fuzzy preference ranking model for a quality evaluation of hospital web sites," International Journal of Intelligent Systems, vol. 21, pp. 1181-1197, 2006.

[3] B. Yılmaz and M. Dağdeviren, "A combined approach for equipment selection: F-PROMETHEE method and zero one goal programming," Department of Industrial Engineering, Faculty of Engineering, Gazi University, vol. 38, pp. 11641-11650, 2011.

[4] G. Dickson, "An analysis of vendor selection systems and decisions," Journal of Purchasing, vol. 2, pp. 28-41, 1966.

[5] C. A. Weber, J. R. Current, and W. C. Benton, "Vendor selection criteria and methods," European Journal of Operational Research, vol. 50 , pp. 2-18, 1991.

[6] S. E. Fawcet, L. L. Stanley, and S. R. Smith, "Developing a logistics capability to improve the performance of international capability to improve the performance of international operations," Journal of Business Logistic, vol. 18, no. 2, pp.101-127, 1997.

[7] S. H. Ghodsypur and C. O'Brien, "A decision support system for supplier selection using an integrated analytic hierarchy process and linear programming," International Journal of Production Economics, vol. 56, pp. 199-212, 1998.

[8] J. Hu, "Supplier selection determination and centralized purchasing decisions," PhD Thesis, Washington State Univercity, 2004.

[9] J. P. Brans and P. H. Vincke, "A preference ranking organization method," Management Science, vol. 31, pp. 647-656, 1985.

[10] J. Geldermann, T. Spengler, and O. Rentz, "Fuzzy outranking for environmental assessmet case study: In and steel making industry," Fuzzy Set Systems, vol. 115, pp. 45-65, 2000.

[11] M. Goumas and V. Lygerou, "An extension of the PROMETHEE metdod for decision making in fuzzy environment: ranking of alternative energy exploitation projects," European Journal of Operational Research, vol. 123, pp. 606-613, 2000.
[12] W. Chou, W. Lin, and C. Lin, "Application of fuzzy theory and PROMETHEE technique to evaluate suitable ecotechnology method: A case study in shihmen reservoir watershed, Taiwan," Ecological Engineering, vol. 31, pp. 269-280, 2007.

[13] K. Zhang, C. Kluck, and G. Achari, "A comparative approach for ranking contaminated sites based on the risk assessment paradigm using fuzzy PROMETHEE," Environmental Management, vol. 44, pp. 952-967, 2009.

[14] Y. Chen, T. Wang, and C. Wu, "Strategic decisions using the fuzzy PROMETHEE for IS outsourcing," Expert System with Application, vol. 38, pp. 13216-13222, 2011.

[15] S. Moradpour, S. Ebrahimnejad, E. Mehdizadeh, A. Mohamadi, "Using hybrid fuzzy PROMETHEE II and fuzzy binary goal programming for risk ranking: A case study of highway construction projects," Journal of Optimization in Industrial Engineering, vol. 9, pp. $47-55,2011$.

[16] R. Gupta, "Selection of logistic service provider using fuzzy PROMETHEE for a cement industry," Journal of Manufacturing Technology Management, vol. 23, no. 7, pp. 899-921, 2012.

[17] T. Chen, "A promethee based outranking method for multiple criteria decision analysis with interval type-2 fuzzy sets," Soft Computer, vol. 18, pp. 923-940, 2014

[18] B. Elevli, "Logistics freight center locations decision by using fuzzy PROMETHEE," Transport, vol. 29, no. 4, pp. 412-418, 2014

[19] Y. Peng, G. Kou, and J. Li, "A fuzzy PROMETHEE Approach for Mining Customer Reviews in Chinese," Arab J SciEng, vol. 39, pp. 5245-5252.

[20] C. Parahinski and W. C. Benton, "Supplier Evaluations: Communication strategies to improve supplier performance," Journal of Operations Management, vol. 22, pp. 39-62, 2004.

[21] F. H. Liu and H. L. Hai, "The voting analytic hierarchy process method for selecting supplier," International Journal Production Economics, vol. 97, pp. 308-317, 2005

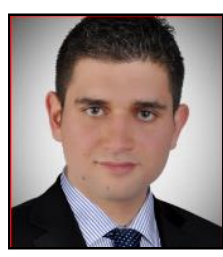

R. Baki was born in Ankara, Turkey, in 1988. He received the degree in industrial engineering from the Gazi University, Ankara, Turkey, in 2011, and the post degrees in industrial engineering from the Gazi University, Ankara, Turkey, in 2014. In 2014, he joined the Department of Management Information Systems, University of Aksaray, as a research assistant. His current research interests include facility layout, multi criteria decision making and production planning. 